\title{
РЕЗУЛЬТАТЫ СТАТИСТИЧЕСКОЙ ОЦЕНКИ ДАННЫХ ГИДРОГЕО- ЛОГО-ГЕОФИЗИЧЕСКИХ ИССЛЕДОВАНИЙ ПРИ ЭКОЛОГИЧЕСКОЙ ОЦЕНКЕ ЭКСПЛУАТИРУЮЩЕГОСЯ ВОДОЗАБОРА
}

\author{
А. А. Аузин, О. М. Муравина, Ю. А. Устименко, Хеляль Марьям Ахмад
}

Воронежский государственный университет

Поступила в редакцию 21 мая 2018 г.

\begin{abstract}
Аннотация: анализ результатов лабораторных исследований проб воды из действующего водозабора позволил установить, что эксплуатируемый водоносный горизонт подпитывается из поверхностного водотока. Это обстоятельство требует обратить особое внимание на соблюдение мер по недопущению загрязнения водосборного бассейна. Результаты математического моделирования связей между параметрами, характеризующими качественные показатели воды, позволяют оценивать достоверность данных.
\end{abstract}

Ключевые слова: питание водоносного горизонта, экологическая обстановка, математическое моделирование, достоверность данных.

\section{THE RESULTS OF THE STATISTICAL EVALUATION OF THE DATA OF HYDROGEOLOGICAL AND GEOPHYSICAL STUDIES IN THE ENVIRONMENTAL ASSESSMENT OF MAINTAINED INTAKE}

\begin{abstract}
: analysis of the results of laboratory studies of water samples from wells to establish that the operated aquifer is associated with the surface watercourse. This result requires special attention to be paid to the implementation of measures to avoid pollution of the catchment area. The results of mathematical modeling of relations between the parameters characterizing the quality indicators of water allow to estimate the reliability of the data.

Key words: he recharge area of the aquifer, ecological, mathematical modeling, the accuracy of the data
\end{abstract}

Метод группового учета аргументов (МГУА), общие положения которого изложены в работах [1-3], был разработан А. Г. Ива́хненко в 80-е годы XX века. Этот метод считается одним из наиболее эффективных средств создания моделей связей между различными параметрами в условиях неполноты информации. Аналогично множественному регрессионному анализу, в процессе моделирования методом МГУА определяется форма связи зависимой переменной и определенного набора независимых переменных. Как правило, последние представляют собой полученные экспериментальным путем параметры, характеризующие некоторые свойства изучаемого объекта. При этом определяется набор параметров, оказывающих наиболее значимое влияние на зависимую переменную. Принципиальным отличием МГУА от методов регрессионного анализа является то, что форма связи не задается заранее, а выбирается из множества моделей, генерируемых в процессе вычислительного эксперимента. Генерация математических моделей осуществляется автоматически с использованием специальных алгоритмов $[2,3]$. Оптимальная модель, как в смысле достоверности, так и степени сложности, находится по минимальным значениям некоторого числа внешних критериев, количество и вид которых определяется решаемой задачей. Лежащий в основе МГУА принцип самоорганизации можно сформулировать следующим образом: при постепенном увеличении сложности модели значение внутренних критериев уменьшается, а внешние критерии проходят через свои минимумы, что позволяет выбрать модель оптимальной сложности.

Таким образом, в процессе идентификации определяется вид уравнения связи между зависимой переменной и влияющих на нее факторов-аргументов. При этом из предложенного набора возможных факторов выбираются наиболее значимые, которые оказывают существенное влияние на зависимую переменную. Реализованные в МГУА идеи синергетики позволяют выявлять скрытую упорядоченность в наборе данных, а также определять наиболее важные процессы и ключевые факторы среди множества взаимодействующих.

Метод МГАУ активно используется на кафедре 
геофизики ВГУ при решении широкого круга прикладных геолого-геофизических задач - построении математических моделей, описывающих зависимости между литотипами пород и соответствующими им геофизическими параметрами; статистической обработке петрофизических данных, трехмерном моделировании геологических объектов и пр. $[1,2]$.

В данной работе представлены некоторые предварительные результаты применения МГУА при установлении взаимосвязей между показателями качества подземных вод одного из водозаборов юга Воронежской области. План водозабора представлен на рис. 1.

Как известно, среди основных показателей качества воды фигурирует жесткость, определяемая содержанием в воде катионов $\mathrm{Ca}^{+2}$ и $\mathrm{Mg}^{+2}$. Причем для Воронежской области именно жесткость является одним из наиболее проблемных параметров, поскольку для большинства её районов содержание солей общей жесткости превышает допустимые значения.

Применительно данному водозабору сложилось мнение, что понижение жесткости поступающей из некоторых его скважин воды обусловлено подпиткой водоносного горизонта из р. Черная Калитва. Для проверки данной гипотезы был выполнен статистический анализ данных лабораторных анализов воды из скважин водозабора с привлечением такого параметpa, как расстояние от обследованной скважины до реки. На рис. 3 приведены данные анализов за 2001, 2003, 2006 и 2010 годы, построенные в координатах жесткость воды - $R$ (расстояние от скважины, из которой отбиралась проба воды, до поверхностного водотока).

Водозабором эксплуатируется турон-коньякский водоносный горизонт, сложенный мелами и мелоподобными мергелями (рис. 2).

Несмотря на существенный разброс точек, можно выделить явный тренд, отражающий увеличение жесткости с ростом $R$. При этом на каждые 100 м увеличения расстояния до водотока жесткость увеличивается на $\sim 0,2$ мг-экв/дм ${ }^{3}$. В качестве объективной причины отдельных «отскоков» от общего тренда значений жесткости может являться то обстоятельство, что продуктивный интервал данной скважины не подпитывается из реки (скв. 52613).

Интересный с практической точки зрения материал получен при попытке установить связь между жесткостью и результатами анализов воды. С использованием аппарата МГАУ была определена формула, связывающая жесткость (мг-экв/дм $\left.{ }^{3}\right)$ и концентрацию $\mathrm{Ca}^{+2}$ и $\mathrm{Mg}^{+2}$ (мг/дм $\left.{ }^{3}\right)$ :

$$
\text { жесткость }=0,3547+0,04752 \mathrm{Ca}^{+2}+0,07841 \mathrm{Mg}^{+2}
$$

На рис. 4 приведено сопоставление значений жесткости, полученных расчетным путем, и приведенных в первоисточнике (отчет по подсчету запасов).

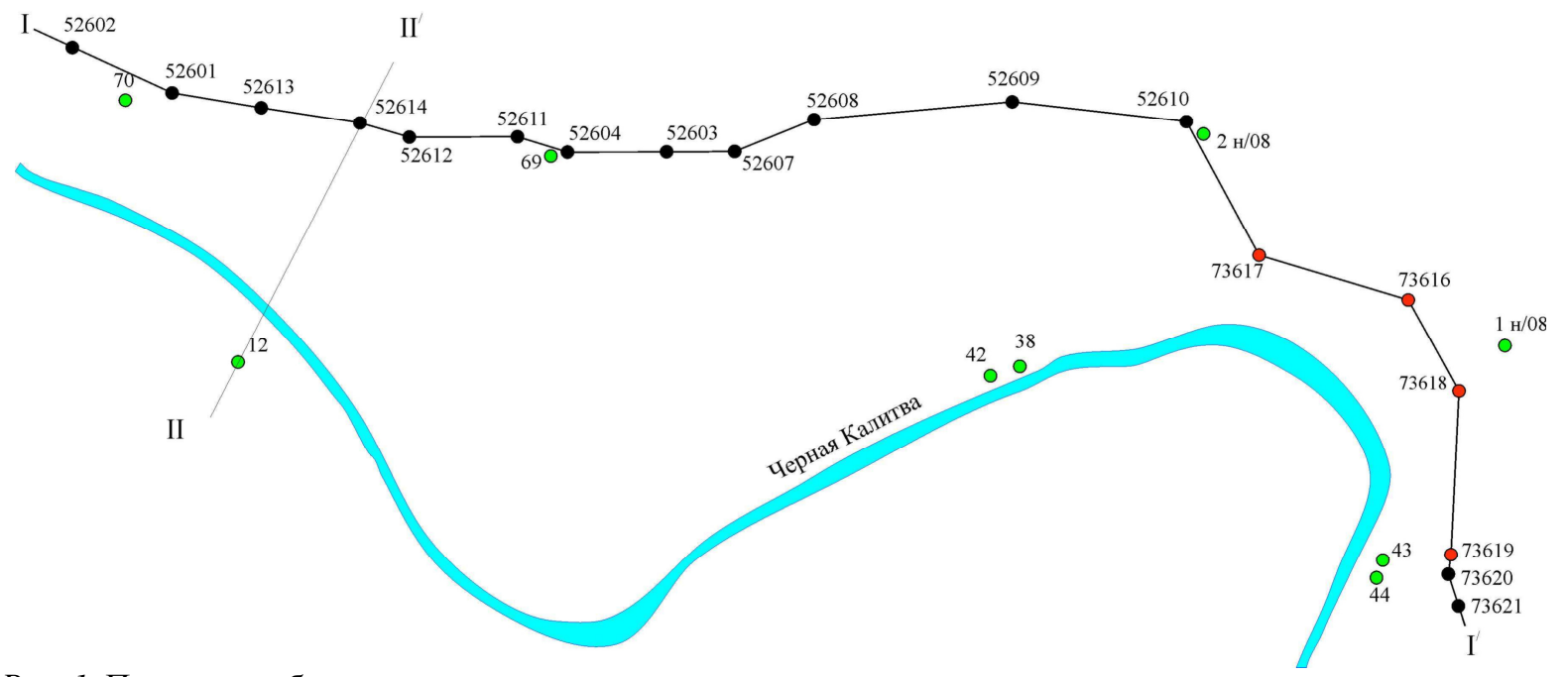

Рuc. 1. План водозабора.

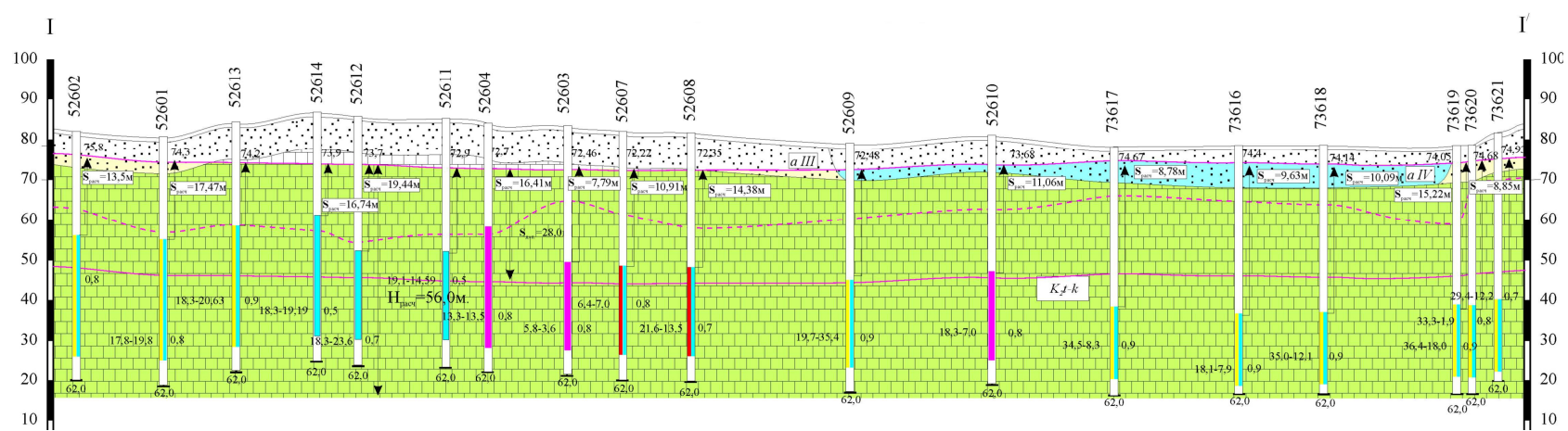

Puc. 2. Схематический гидрогеологический разрез по линии I - I'. 

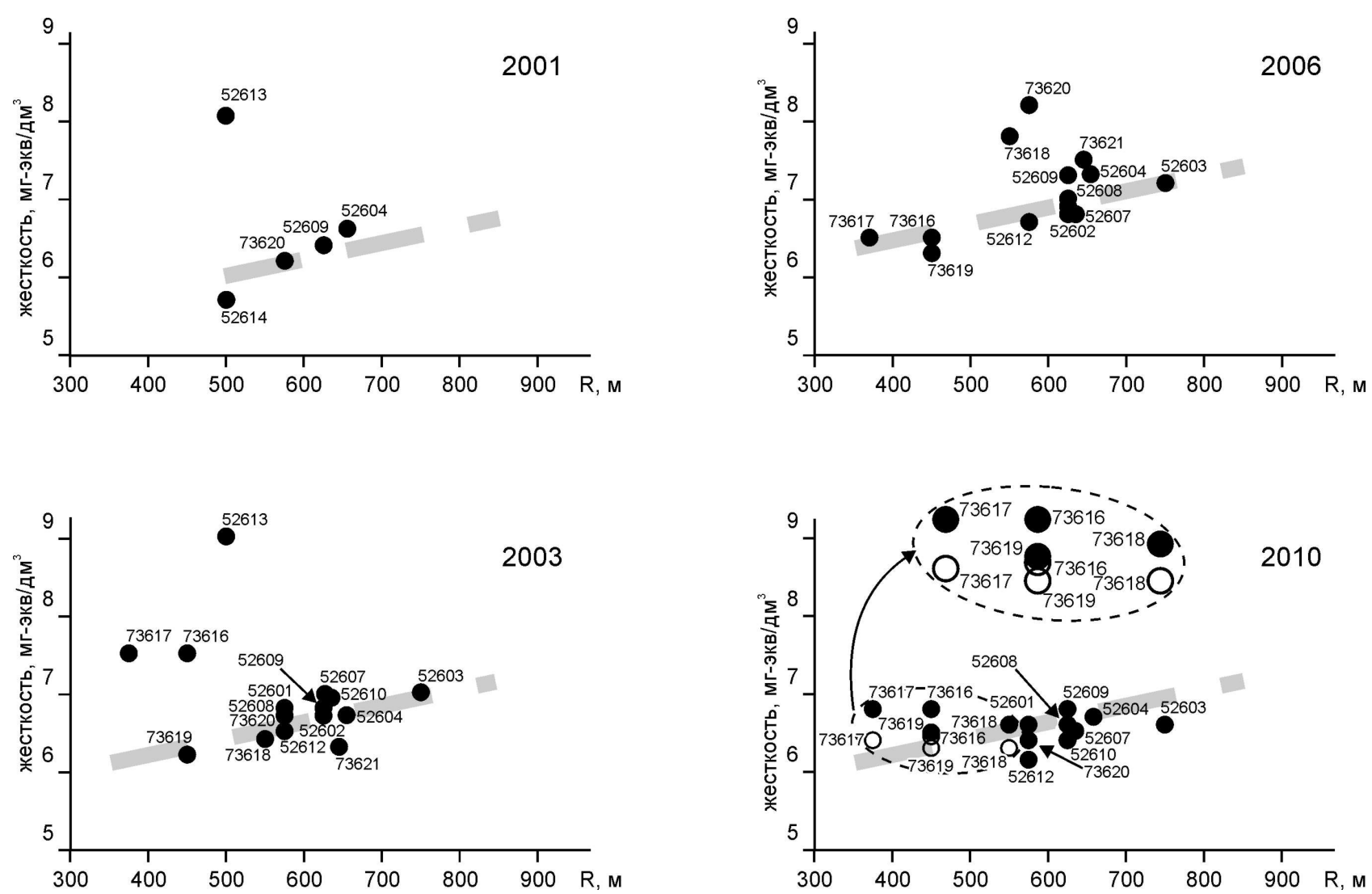

$P u c$. 3. Зависимость жесткости воды от расстояния от опробованной скважины до поверхностного водотока $(R)$.

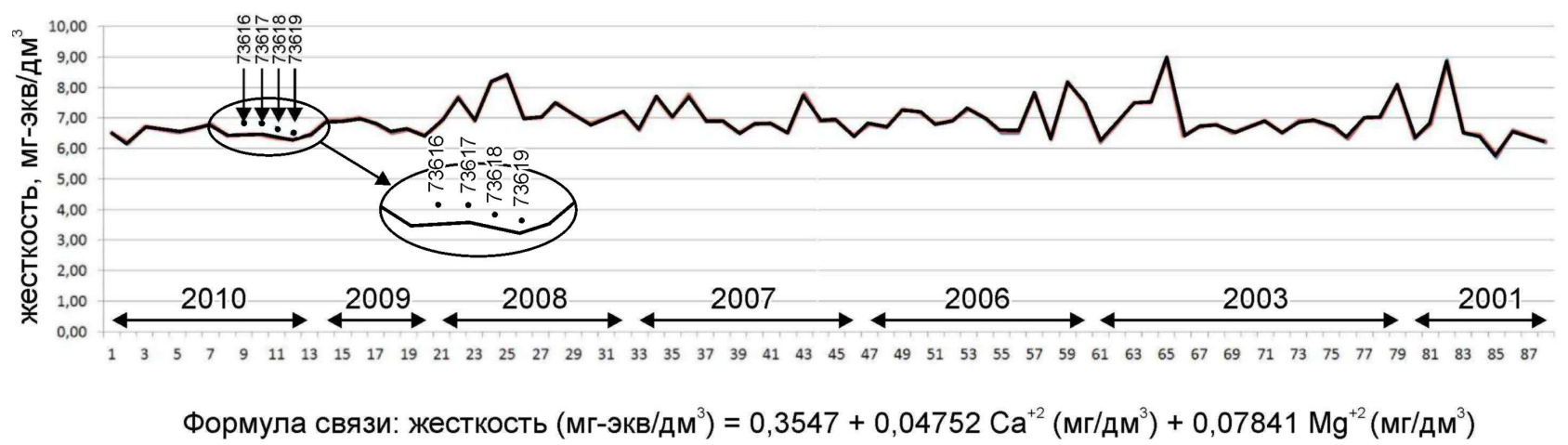

Puc. 4. Значения жесткости воды, рассчитанные по формуле (1) (сплошная линия), и приведенные в первоисточнике (точечная линия).

Поскольку жесткость воды является расчетным параметром и вычисляется по содержанию в ней катионов $\mathrm{Ca}^{+2}$ и $\mathrm{Mg}^{+2}$, которые определяются лабораторными методами, то совершенно очевидно, что результаты расчетов жесткости должны полностью соответствовать материалам первоисточника. Именно так это и происходит во всех случаях, за исключением данных по скважинам 73616, 73617, 73618 и 73619 за 2010 г. Что характерно - результаты расчетов существенно лучше отвечают выявленному тренду зависимости жесткости от расстояния между опробуемой скважиной и водотоком (не залитые кружки на рис. 3).
По результатам выполненных исследований можно сделать заключение о том, что большая часть эксплуатируемых скважин водозабора подпитывается рекой Черная Калитва. Это обстоятельство вынуждает обратить пристальное внимание на поддержание стабильной экологической ситуации на территории, прилегающей к акватории реки. Тем более что эта территория подвержена значительной антропогенной нагрузке.

Для определения фактических параметров подземных водотоков, в скважинах водозабора (как наблюдательных, так и эксплуатационных) необходимо провести специальный комплекс геофизических 
исследований, в том числе и при различных режимах эксплуатации водозабора [4].

Моделирование параметров природных объектов, выполняемое по экспериментальным данным с привлечением метода группового учета аргументов, позволяет оценить качество исходных данных, что дает возможность не только выявить случайно возникшие (или намеренно внесенные) ошибки, но и скорректировать их.

Работа выполнена при поддержке гранта РФФИ 18-05-00226

Воронежский государственный университет

Аузин Андрей Альбертович, доктор технических наук, профессор кафедры геофизики геологического факультета E-mail: AAuzin@yandex.ru

Тел.: 8-473-220-83-85

Муравина Ольга Михайловна, доктор технических наук, доиент кафедры геофизики геологического факультета E-mail:Comovo@yandex.ru

Тел.: 8-473-220-83-85

Устименко Юрий Алексеевич, заместитель директора научно-исследовательского института геологии. E-mail: gidrogeol@mail.ru; Тел.: 8-473-220-89-80

Хеляль Марьям Ахмад, Сирийская Арабская Республика, аспирант кафедры геофизики геологического факультета E-mail: maryam.he@hotmail.com

Tel.: 8-473-220-89-80

\section{ЛИТЕРАТУРА}

1. Аузин, A. A. О возможности оптимизации комплексов геофизических исследований в скважинах при поисках месторождений рудных полезных ископаемых. / А. А. Аузин, О. М. Муравина // Вестник Воронеж. гос. ун-та. Сер.: Геология. - 2013. - № 1. - С. 184-188.

2. Аузин, A. A. Статистический анализ данных каротажа методом группового учета аргументов. / А. А. Аузин, О. М. Муравина // Вестник Воронеж. гос. ун-та. Сер.: Геология. 2010. - № 2. - С. 219-224.

3. Ивахненко, А. Г. Индуктивный метод самоорганизации моделей сложных систем. / А. Г. Ивахненко - Киев : Наук. думка, 1982. - $296 \mathrm{c}$.

4. Аузин, А. А. Комплексирование методов геофизических исследований в скважинах (на примере Воронежской антеклизы). / А. А. Аузин- Воронеж : Изд-во «Научная книга», 2010. - 260 c.

\section{Voronezh State University}

Auzin A. A., the doctor of Technical Science, professor of the Geophysical department of Geological faculty

E-mail: AAuzin@yandex.ru

Tel.: 8-473-220-83-85

Muravina O. M., the doctor of Technical Science, docent of the Geophysical department of Geological faculty

E-mail:Comovo@yandex.ru

Tel.: 8-473-220-83-85

Ustimenko Y. A., deputy director of Research Institute of Geology E-mail: gidrogeol@mail.ru

Tel. 8-920-454-21-49

Maryam Ahmad Helal, the post-graduate student of the Geophysical department of Geological faculty

E-mail: maryam.he@hotmail.com

Tel.: 8-920-454-21-49 